Article

\title{
Carbon Nanoparticle-Based Electro-Thermal Building Block
}

\author{
Mohammad Taghi Ahmadi $1,2, * \mathbb{B}$, Neda Mousavi ${ }^{3}$, Truong Khang Nguyen ${ }^{1,2}$, \\ Seyed Saeid Rahimian Koloor $4, *($ i) and Michal Petrů 4 (i) \\ 1 Division of Computational Physics, Institute for Computational Science, Ton Duc Thang University, \\ Ho Chi Minh City 758307, Vietnam; tknguyen@tdtu.edu.vn \\ 2 Faculty of Electrical and Electronics Engineering, Ton Duc Thang University, \\ Ho Chi Minh City 758307, Vietnam \\ 3 Nano-Electronic Research Group, Physic Department, Nano-Technology research center, Urmia University, \\ Urmia 57147, Iran; n.mousavi@urmia.ac.ir \\ 4 Institute for Nanomaterials, Advanced Technologies and Innovation, Technical University of Liberec, \\ Studentska 2, 46117 Liberec, Czech Republic; michal.petru@tul.cz \\ * Correspondence: ahmadiph@tdtu.edu.vn (M.T.A.); seyed.rahimian@tul.cz (S.S.R.K.)
}

Received: 26 June 2020; Accepted: 21 July 2020; Published: 25 July 2020

\begin{abstract}
All around the world, researchers have raised concerns about the superlative geometrical, electronic, thermal, chemical and mechanical properties of carbon nanoparticles (CNPs). CNPs with low cost, high performance and prominent intrinsic properties have attracted extensive interest for numerous applications in various fields. Although CNPs have been studied mainly as transistors and sensors, they could also be considered as heat producers. However, this option has scarcely been studied. In this research, a CNP-based electro-thermal building block is synthesized by the arc discharge method in a carbonic medium (high-density polyethylene), and its behavior is investigated. It is shaped in the form of a metal-semiconductor-metal structure (MSM) between metallic electrodes, and in addition, the formation of two back-to-back Schottky diodes is analyzed and their use as CNP-based electro-thermal building blocks are reported.
\end{abstract}

Keywords: carbon nanotubes; electro-thermal heating element; arc discharge; heat production; temperature-dependent electrical resistance

\section{Introduction}

Carbon nanoparticles (CNPs) have caught the significant attention of researchers due to their outstanding electrical, mechanical and optical properties that make them useful components in various fields, such as lithium ion batteries, transistors, diodes, logic gates, sensors and field emitter manufacturing. On the other hand, CNP composites are well known for their physical, chemical and especially electrical properties [1] but heat generation by these materials is a device-limiting factor. However, as an electro-thermal component, they have scarcely been studied, although their thermal effect in the form of a CNP and high-density polyethylene (HDPE) interconnected network inside a polymer matrix has been reported [2,3]. It is notable that CNP-based heating elements indicate great potential as industrial equipment because of their light weight, clean energy production without the emission of by-products, controllability and low production cost [4-7]. For example, the heating capacity of Single wall carbon nanotube (SWCNT) films by coating them in glass, regarding the time and input power, indicates a rapid thermal response and stable reversibility [8]. Additionally, multi wall carbon nanotubes (MWCNTs) can be used as temperature sensors, which has been revealed by electrical resistance investigations of free-standing MWCNT films versus temperature [9]. Moreover, 
the conductive MWCNT/polymer composite has been used as a stain sensor by characterizing its electrical properties [10]. Additionally, carbon nanotubes (CNTs) have been reported as conductive filler materials in polymer composites, which are useful for controlling the temperature in these composites as heating elements or sensors [11]. In addition, several studies reported on the application of nanoparticles such as CNTs, graphene and silver nanowires in flexible transparent thin film heaters [12,13]. Additionally, the effect of electro-thermal heating on CNT/polymer composites has been measured and it was indicated that the thermal degradation of $\mathrm{CNT} /$ polymer composites is more than for air convection heating [14]. Furthermore, the CNT ratio in the polymer composites as an important factor has been reported and it was indicated that a higher CNT ratio leads to a higher conductivity [15]. Since the performance of an electro-thermal device can be simulated by its electrical resistivity (slope of the V-I characteristic), that converts electrical energy into thermal energy, therefore, this report is focused on current-voltage (I-V) characteristic analysis. The current flow consequently determines the amount of thermal energy and heat generation, and thermal energy can be controlled by controlling the CNP resistance as well [16-19]. Accordingly, examining different samples with different electrodes plus changing the distances between the electrodes gives rise to the investigation of temperature-dependent CNP networks [20-22]. In this research, CNPs are synthesized by the arc discharge method in a carbonic medium (high-density polyethylene), and heat production based on fabricated CNPs as an electro-thermal building block is explored.

\section{Experimental Framework}

In this study, CNPs are obtained by the pulsed arc discharge method which is done by employing a pulsed high voltage inverter, as shown in Figure 1. To raise the HDPE temperature to the melting point, it is placed inside a quartz tube on top of a heater and the next step is to measure the I-V characteristic with a signal generator together with an oscilloscope. Finally, the presence of DC voltage-transmitted heat by a non-contact thermometer, which is focused on the CNPs, is investigated.

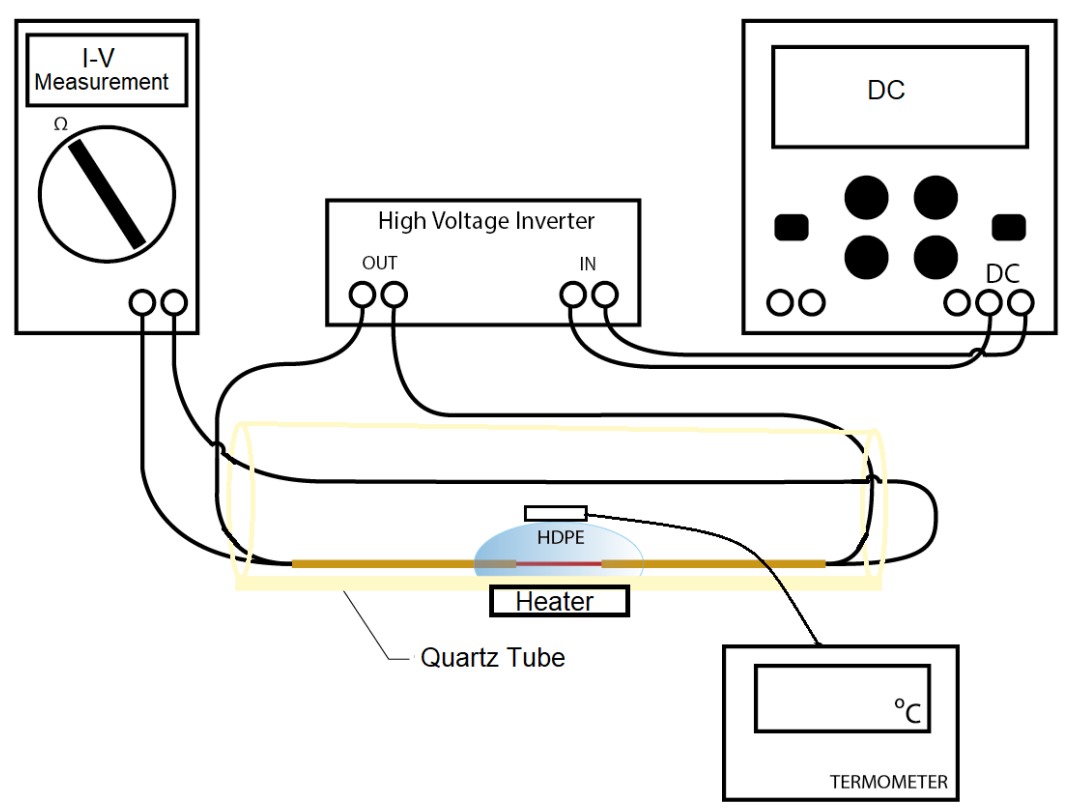

Figure 1. The schematic presentation of the experimental setup.

In this method, two pointed rods (either steel rods (for results and comparison, see Appendix A) with $0.5 \mathrm{~mm}$ diameters or graphite rods with $2 \mathrm{~mm}$ diameters are used as electrodes and are placed face to face inside a carbonic source (HDPE), as shown in Figure 2. The HDPE polymer is heated up to its melting point which provides the spark path inside the carbonic polymer that is being used as a carbon source. 


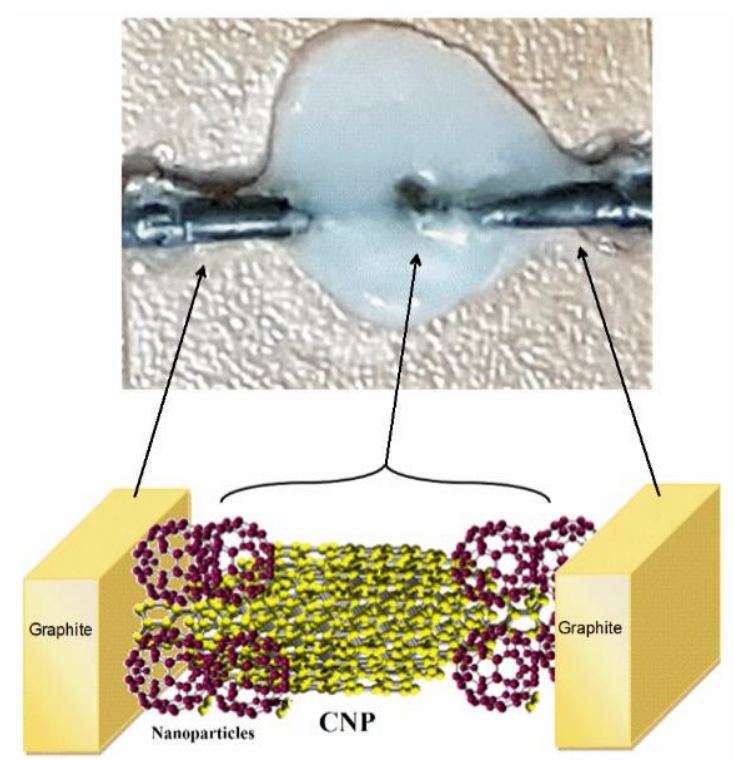

Figure 2. The real device (top), and its schematic representation (bottom).

The potential of a few $\mathrm{kV}$ between two electrodes is generated by the high-voltage system when the polymer is melted, which leads to the creation of plasma in the quartz chamber and the ionization of the HDPE carbon source. Therefore, by breaking the molecular bonds of the polymer and separating the carbon atoms, the carbon ions are accumulated on the tips of both electrodes and grow until they are joined to each other, and this process leads to CNP production. Consequently, a complete circuit is created and therefore electric charges can flow. It is notable that all measurements are done in ambient conditions (temperature $=300 \mathrm{~K}$, pressure $=1 \mathrm{~atm}$ ). Additionally, the produced nanoparticles are surrounded by an HDPE-polymer composite, which makes the fabricated device more stable and increases the strength of the structure [23,24]. This type of arrangement is known as a metal-semiconductor-metal (MSM) structure, with two back-to-back Schottky diodes. Our sample mainly consists of multiwall CNTs (MWCNTs) that have been previously reported in several analyses by our team to have a size on the nanometer scale [25-29]. In addition, as shown in Figure 3a, a finger-shaped qualitative surface morphology is identified by scanning electron microscopy (SEM) and in the focused part, the presence of cylindrical nanoparticles a few hundred nanometers in size is revealed (Figure 3b).

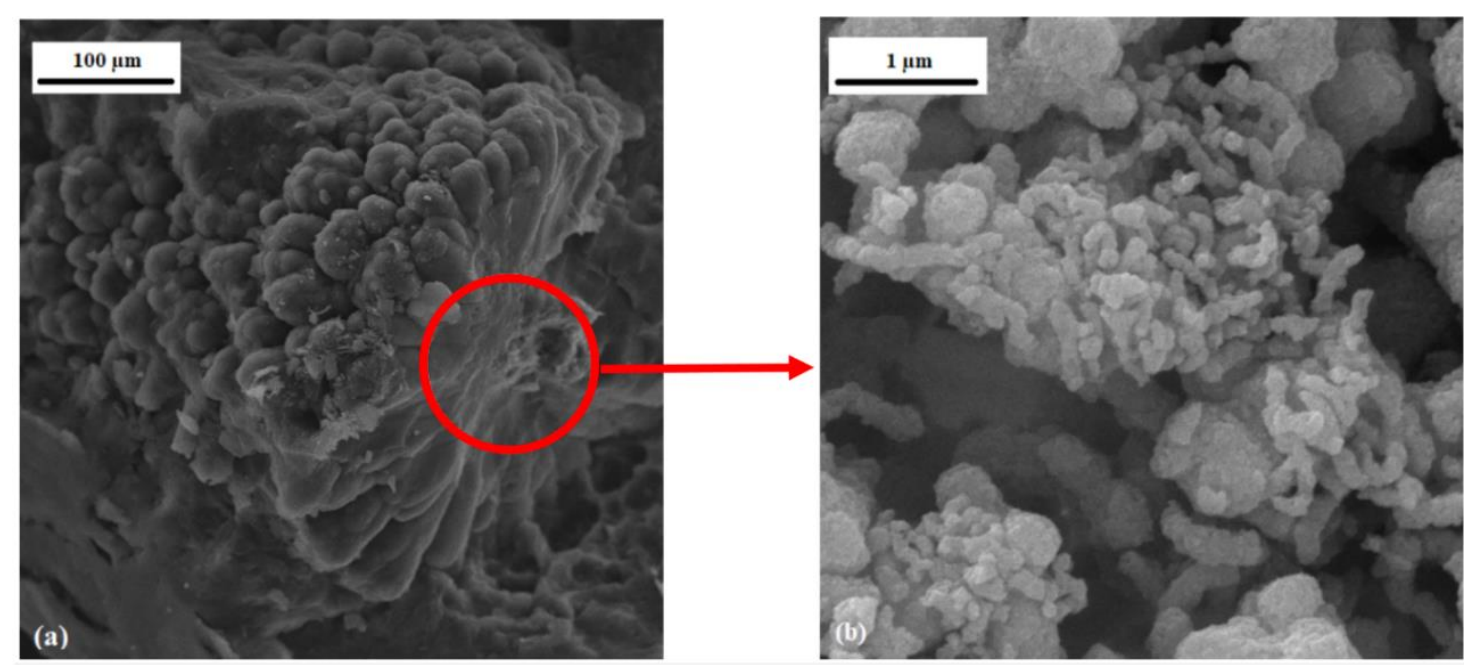

Figure 3. SEM images of (a) a bulk nanoparticle strand and (b) a zoomed in image of the marked area in (a), which displays the presence of cylindrical nanoparticles in the core of the synthesized strand. 
According to the SEM images, the excess MWCNTs that are overlaid by HDPE chains similar to the composites reported by W. Ding et al. [23] are realized. Additionally, the nano-focus image of the fabricated CNPs is carried out, as shown in Figure 4, which leads to the estimated size of the particles.
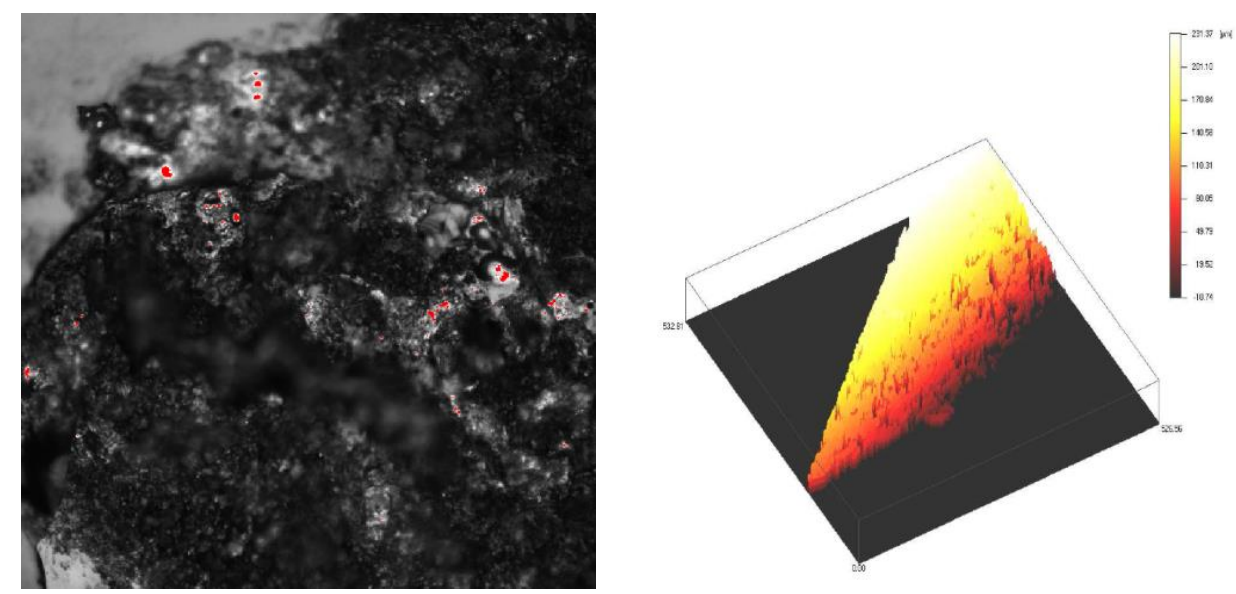

Figure 4. The nano-focus image of the carbon strand surface (left) and random illustration of the carbon nanoparticle (CNP) strand surface. The right image shows the position of points -10 to 231 micrometers apart on the surface.

As shown in Figure 4 (for high resolution, see Appendix B), on the surface of the carbon strand, the minimum and maximum points are about 240 micrometers away from each other which, based on the SEM image, can be used as a CNP length indicator as well. The surface analysis indicates numerous micro-cracks in the strand which form a mechanically delicate structure in the fabricated strand since the strand structure is covered by a polymer network and the strand is stable for typical electro-thermal element applications.

To investigate the performance of the CNP-polymer composite as an electrical heating building block, continuous DC power is applied to the fabricated MSM structure with graphite electrodes. Furthermore, the temperature variation is analyzed by a non-contact infrared thermometer with a $0.1 \mathrm{~K}$ accuracy. The corresponding characteristics are demonstrated in Figures 5-8 for three samples with graphite electrodes that stay close to the same initial resistances, named A, B and C.

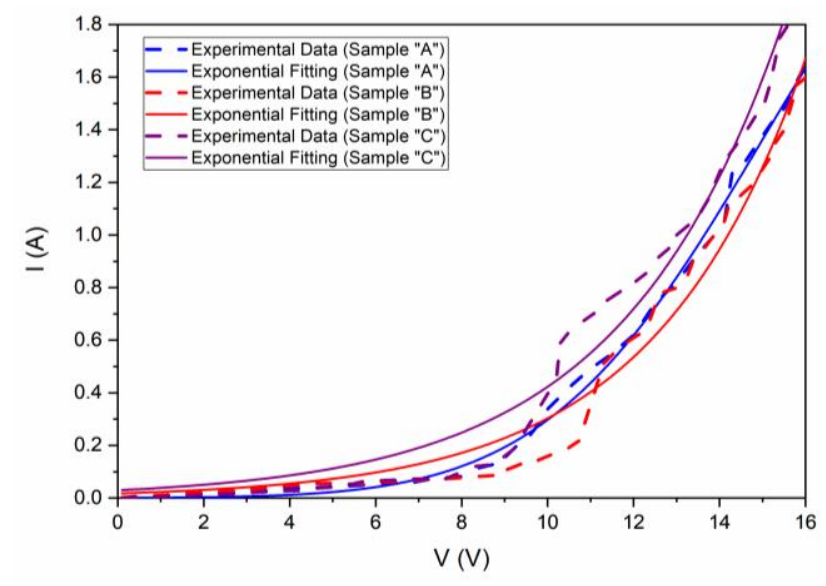

Figure 5. Current-voltage (I-V) characteristics of the CNP-based graphite samples.

As can be seen from the graph in Figure 5, the I-V characteristics of the CNP-based devices show the same non-Ohmic behavior that can be expressed in semiconducting materials. Moreover, electrical current flow in the CNP-based devices gives rise to heat production, so they are considered as a heating 
device in this research. In addition, the variation of temperature as a function of the applied voltage is measured and shown in Figure 6.

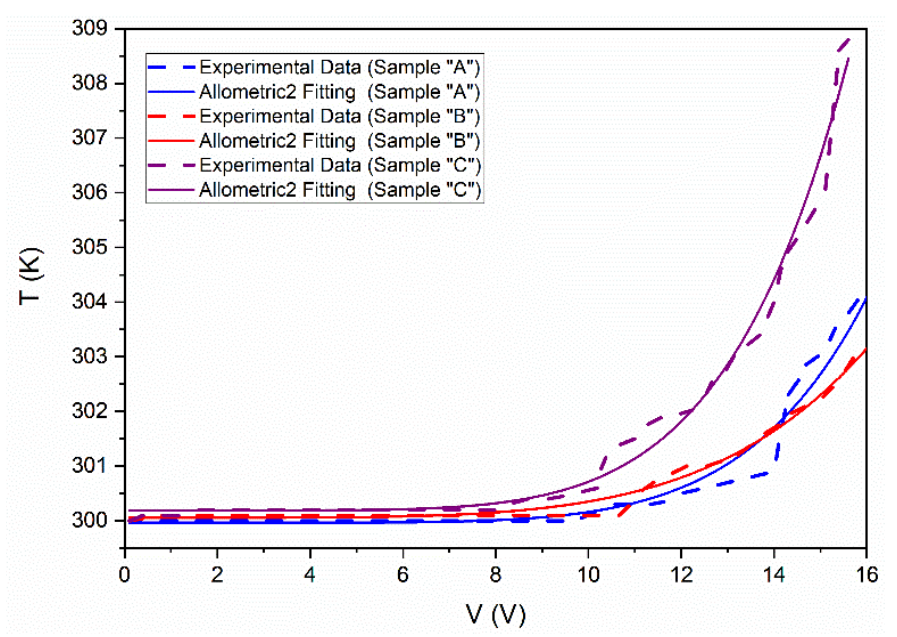

Figure 6. Temperature variation versus applied voltage for CNP-based electro-thermal components with graphite electrodes.

As shown in Figure 6, the experimental data are fit to a nonlinear equation $y=a+b \times x^{c}$ by using the Levenberg-Marquardt algorithm, which indicates a clear trend of increasing temperature by increased applied voltage in all samples by graphite electrodes. Correspondingly, it is concluded that for small voltages from zero up to 7 volts, there is not a significant temperature variation due to applied voltage, but for voltages more than 8 , a dramatic temperature variation for the applied voltage is reported, which can be expressed as a heat generation threshold voltage. It is eminent that for all samples, temperature variations are proportional to the current deviation, in the other words, since sample $C$ passes more current, it therefore generates higher thermal energy as well. Based on the experimental data, the resistance variations under applied voltages are extracted and it is shown that the resistance variation of the CNP-based MSM structures under applied voltage is initially increased, but decreases with higher applied voltages, as shown in Figure 7.

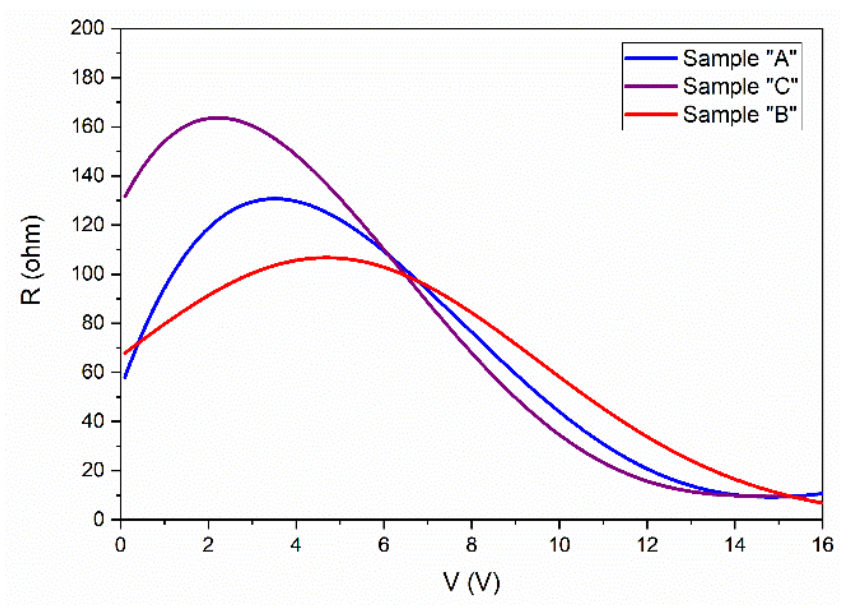

Figure 7. Extracted resistance variation under applied voltage for CNP-based metal-semiconductormetal (MSM) structures with graphite electrodes.

From the resistance variation, it can be seen that the resistance value increases notably by voltage in all samples for small applied voltages but decreases in higher applied voltages, which can be explained by the semiconducting behavior of synthesized samples as a basic phenomenon in the heat 
emission process. Furthermore, extracted resistance variation by temperature change is shown in Figure 8.

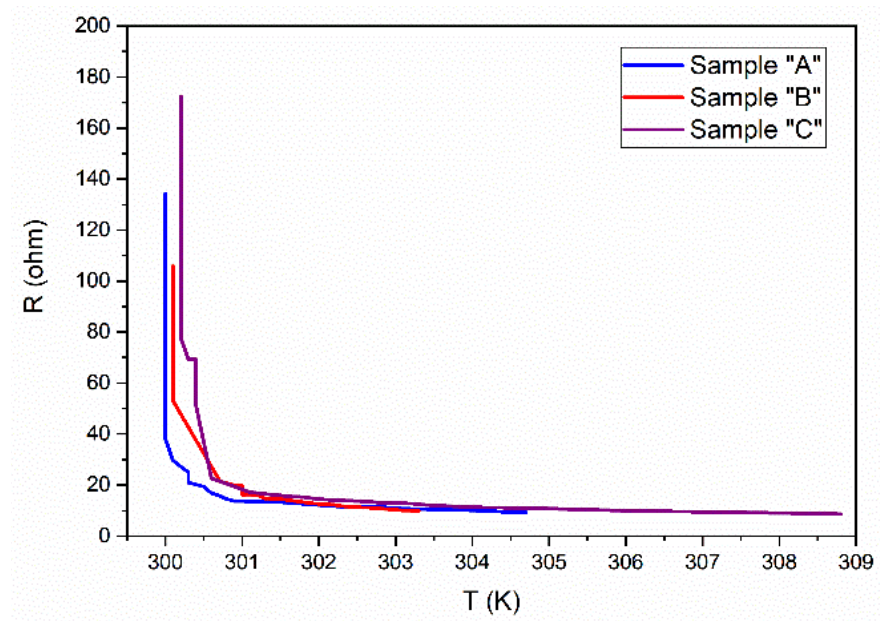

Figure 8. Resistance deviation with respect to the generated temperature of the CNP-based electro-thermal device with graphite electrodes.

It is concluded that the value of resistance decreases significantly with increased temperature during the heat generation process which is similar to the non-Ohmic materials. Additionally, it gives evidence for the semiconducting behavior of synthesized samples. On the other hand, in two terminal devices, such as diodes or Schottky contacts, the Schottky equation is mainly responsible for the current voltage characteristic:

$$
\mathrm{I}=\mathrm{I}_{\mathrm{s}}\left(\mathrm{e}^{\frac{\mathrm{v}}{\mathrm{nv}_{\mathrm{T}}}}+1\right)
$$

where $\mathrm{n}, \mathrm{v}$ and $\mathrm{v}_{\mathrm{T}}$ are the ideal factor, applied voltage and thermal voltage $=\mathrm{e}$, respectively (in the presented model, $\mathrm{I}_{\mathrm{S}}=1$ micro $\mathrm{A}, \mathrm{v}$ as a variable, $\mathrm{v}_{\mathrm{T}}=0.026$, and $\mathrm{v}$ and $\mathrm{n}$ as fitting parameters are considered). In addition, in the presented equation, the saturation current in the doped semiconductor junction can be calculated by:

$$
\mathrm{I}_{\mathrm{s}}=\mathrm{qn}^{2} \mathrm{~A}\left(\frac{\mathrm{D}_{\mathrm{n}}}{\mathrm{N}_{\mathrm{A}} \mathrm{L}_{\mathrm{n}}}+\frac{\mathrm{D}_{\mathrm{pn}}}{\mathrm{N}_{\mathrm{D}} \mathrm{L}_{\mathrm{p}}}\right) .
$$

where A, Ln, Lp, Dn and Dp are the area, electron diffusion length, hole diffusion length and electron or hole diffusivity, respectively. As shown in Figure 9, most CNP-based nano-strands follow the Schottky trend.

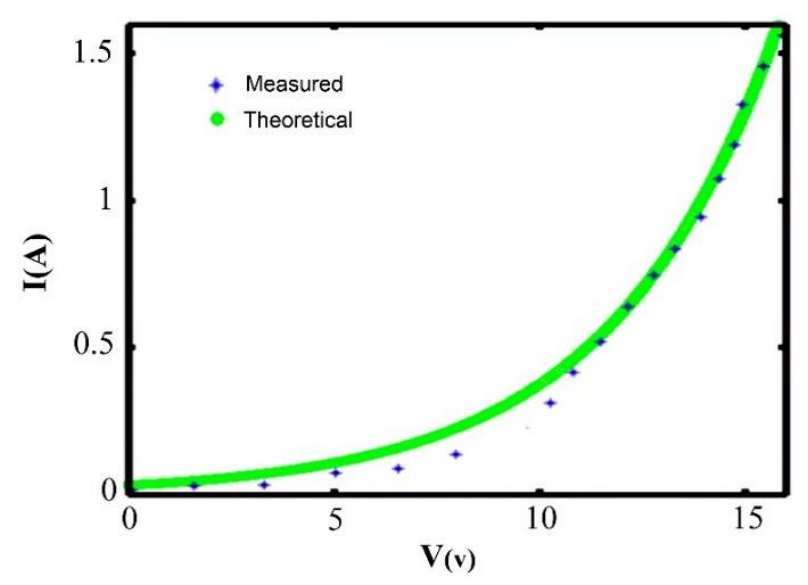

Figure 9. The comparison between the behavior of fabricated CNPs and the theoretical aspect. 
As indicated in Figure 9, an acceptable agreement between the Schottky model and the produced CNP-based strands is reported, therefore, the material can be categorized as a non-Ohmic material. Moreover, based on the analyzed data, it is shown that by increasing the emitted heat from the samples, the resistance value is decreased. In the other words, the temperature escalation in the CNP-based building block is associated with the common temperature-dependent behavior of non-Ohmic materials.

\section{Conclusions}

Effective and accurate heating devices with industrial and laboratory applications lead to the utilization of new methods and resources, such as carbon-based materials. The low production cost, as well as the remarkable property of CNPs, recommends their application in device development processes. Therefore, in this research, a CNP-based strand structure is introduced as a heating building block. Moreover, its different characteristic parameters are analyzed for the synthesized samples. Additionally, its behavior under fundamental theoretical work is confirmed and an acceptable agreement is reported. Furthermore, the results indicate that the temperature increases by enlarging the applied voltage value. Thus, temperature variation can be controlled by applied voltage on the CNP-based heating element. In industrial heating elements, a series of CNP networks is suggested, which causes a higher temperature rise. Since the CNP-based electro-thermal components are almost stable structures in the presence of very high temperatures, together with their cheap production methods, this encourages us to nominate them as future heating elements.

Author Contributions: Conceptualization, M.T.A.; methodology, M.T.A., and N.M.; software, M.T.A., and N.M.; validation, M.T.A., N.M., T.K.N., S.S.R.K., and M.P.; formal analysis, M.T.A., N.M., and S.S.R.K.; investigation, M.T.A., N.M., T.K.N.; resources, M.T.A., T.K.N., S.S.R.K., and M.P.; data curation, M.T.A., and N.M.; writing-original draft preparation, M.T.A., and N.M.; writing-review and editing, M.T.A., N.M., T.K.N., S.S.R.K., and M.P.; visualization, M.T.A., and S.S.R.K.; supervision, M.T.A., and S.S.R.K.; project administration, M.T.A., T.K.N., S.S.R.K., and M.P.; funding acquisition, M.T.A., S.S.R.K., and M.P. All authors have read and agreed to the published version of the manuscript.

Funding: This work was funded by Ton Duc Thang University, Ho Chi Minh City, Vietnam. The research was also supported by the Ministry of Education, Youth, and Sports of the Czech Republic and the European Union (European Structural and Investment Funds Operational Program Research, Development, and Education) in the framework of the project "Modular platform for autonomous chassis of specialized electric vehicles for freight and equipment transportation", Reg. No. CZ.02.1.01/0.0/0.0/16_025/0007293, as well as the financial support from internal grants in the Institute for Nanomaterials, Advanced Technologies and Innovations (CXI), Technical University of Liberec (TUL).

Conflicts of Interest: The authors declare no conflict of interest.

\section{Appendix A. I-V, R-T and R-V Characteristics for MSM Structures with Steel Electrodes}

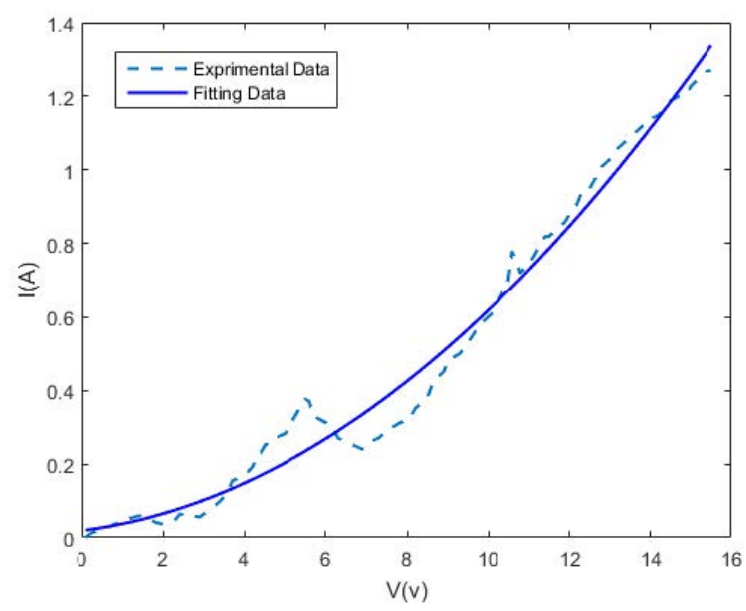

Figure A1. Characteristics of the CNP-based electro-thermal MSM with steel electrodes. 


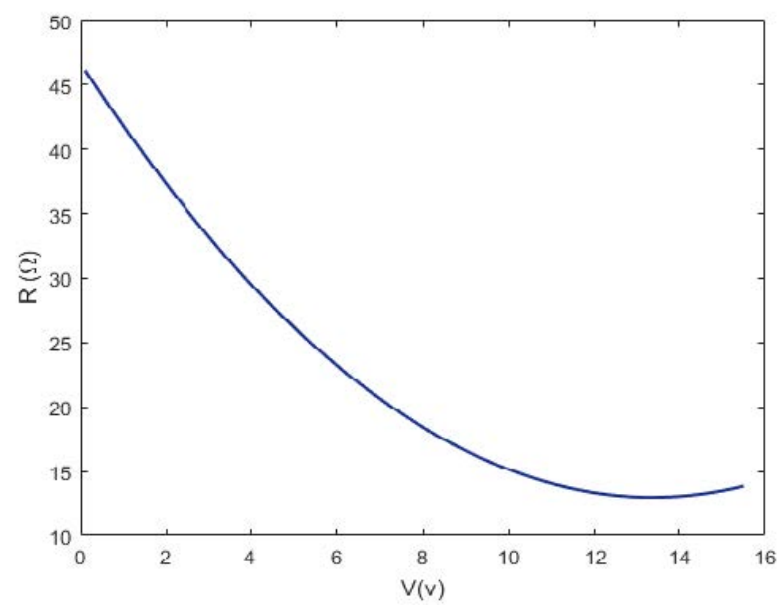

Figure A2. Extracted resistance variation under applied voltage for the MSM with steel electrodes.

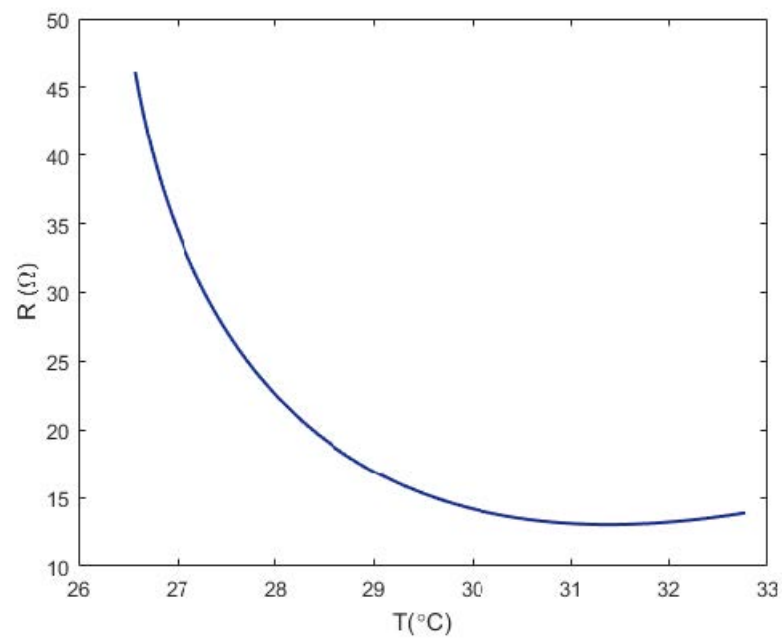

Figure A3. Extracted resistance deviation with respect to the generated temperature in the CNP-based MSM with steel electrodes.

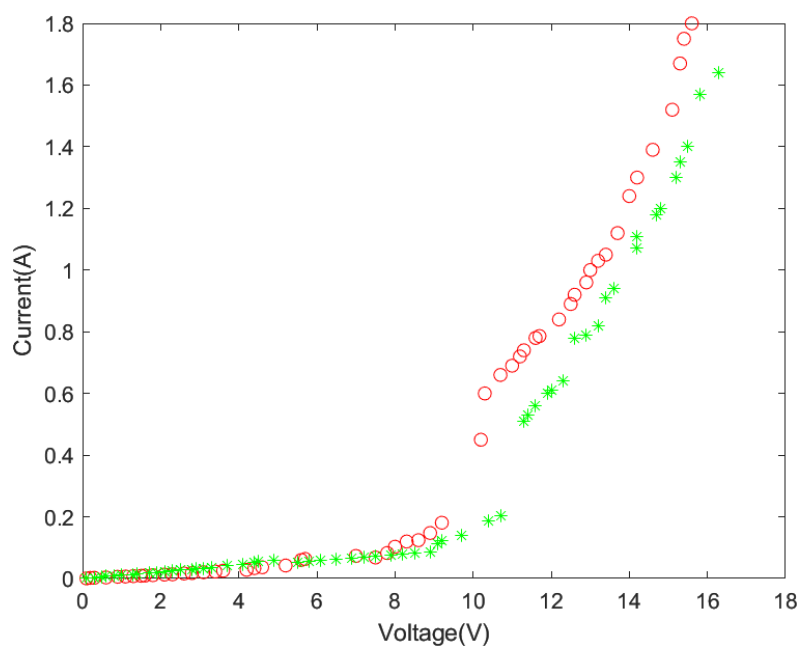

Figure A4. The I-V characteristic comparison between fabricated CNPs with steel (green) and graphite (red) electrodes which indicate the same behavior. 


\section{Appendix B.}

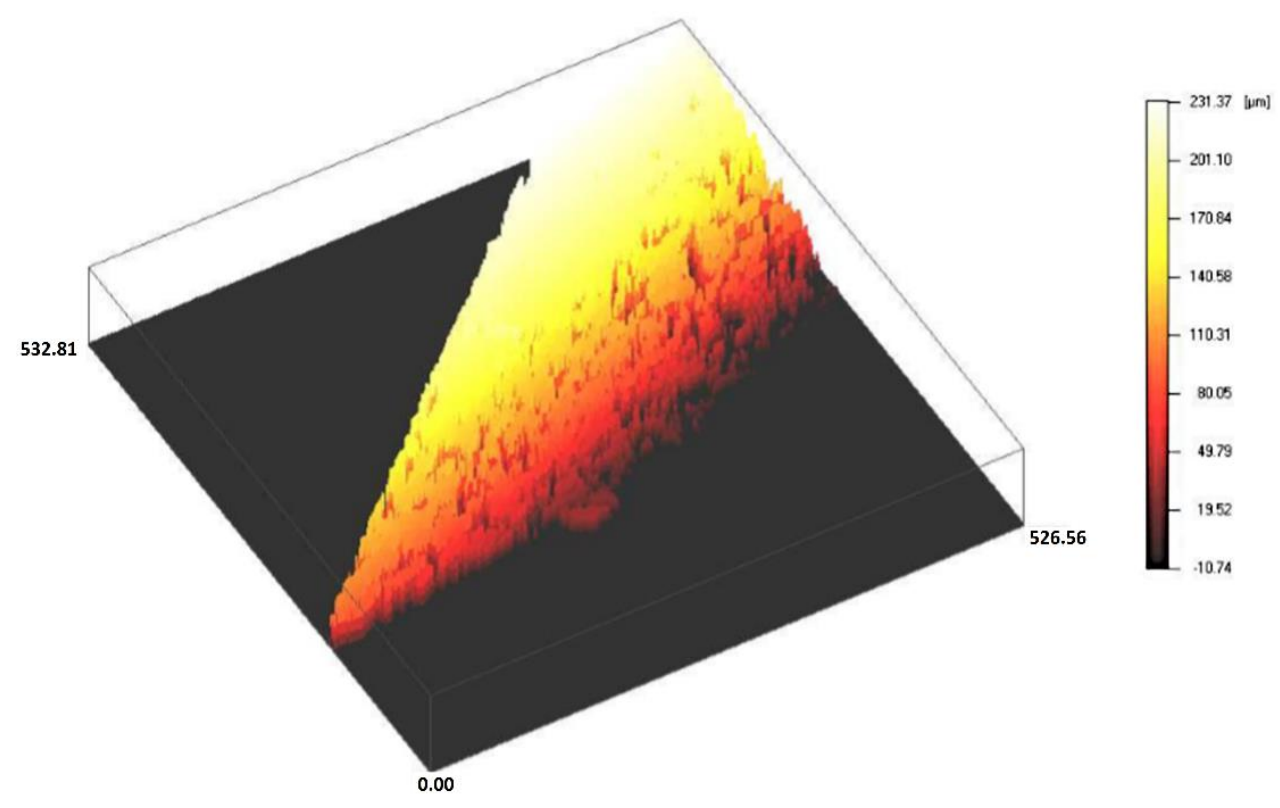

Figure A5. High-resolution nano-focus image.

\section{References}

1. Meng, X.; Chen, T.; Li, Y.; Liu, S.; Pan, H.; Ma, Y.; Chen, Z.; Zhang, Y.; Zhu, S. Assembly of carbon nanodots in graphene-based composite for flexible electro-thermal heater with ultrahigh efficiency. Nano Res. 2019, 12, 2498-2508. [CrossRef]

2. Zhou, Y.; Wang, X.; Liu, X.; Sheng, D.; Ji, F.; Dong, L.; Xu, S.; Wu, H.; Yang, Y. Polyurethane-based solid-solid phase change materials with halloysite nanotubes-hybrid graphene aerogels for efficient lightand electro-thermal conversion and storage. Carbon 2019, 142, 558-566. [CrossRef]

3. Mandal, P.; Mondal, S.C. Enhancement of electro-thermal and mechanical properties for Cu-SWCNT coated 6061Al. Surf. Eng. 2020, 36, 135-143. [CrossRef]

4. Artukovic, E.; Kaempgen, M.; Hecht, D.S.; Grüner, G. Transparent and flexible carbon nanotube transistors. Nano Lett. 2005, 5, 757-760. [CrossRef]

5. Derycke, V.; Martel, R.; Appenzeller, J.; Avouris, P. Carbon nanotube inter-and intramolecular logic gates. Nano Lett. 2001, 1, 453-456. [CrossRef]

6. Valentini, L.; Armentano, I.; Kenny, J.C.; Cantalini, L.; Lozzi, S. Santuccci. Appl. Phys. Lett. 2003, 82, 961. [CrossRef]

7. Huang, N.; She, J.; Chen, J.; Deng, S.Z.; Xu, N.S.; Bishop, H.; Huq, S.E.; Wang, L.; Zhong, D.Y.; Wang, E.G.; et al. Mechanism responsible for initiating carbon nanotube vacuum breakdown. Phys. Rev. Lett. 2004, 93, 075501. [CrossRef] [PubMed]

8. He, X.J.; Du, J.H.; Ying, Z.; Cheng, H.M. Positive temperature coefficient effect in multiwalled carbon nanotube/high-density polyethylene composites. Appl. Phys. Lett. 2005, 86, 062112. [CrossRef]

9. Jeong, Y.G.; Jeon, G.W. Microstructure and Performance of Multiwalled Carbon Nanotube/m-Aramid Composite Films as Electric Heating Elements. ACS Appl. Mater. Interfaces 2013, 5, 6527-6534. [CrossRef]

10. Lekawa-Raus, A.; Walczak, K.; Kozlowski, G.; Wozniak, M.; Hopkins, S.; Koziol, K.K. Resistance-temperature dependence in carbon nanotube fibres. Carbon 2015, 84, 118-123. [CrossRef]

11. Dehghani, S.; Moravvej-Farshi, M.K.; Sheikhi, M.H. Temperature dependence of electrical resistance of individual carbon nanotubes and carbon nanotubes network. Mod. Phys. Lett. B 2012, 26, 1250136. [CrossRef]

12. Yoon, Y.H.; Song, J.W.; Kim, D.; Kim, J.; Park, J.K.; Oh, S.K.; Han, C.S. Transparent film heater using single-walled carbon nanotubes. Adv. Mater. 2007, 19, 4284-4287. [CrossRef] 
13. Di Bartolomeo, A.; Sarno, M.; Giubileo, F.; Altavilla, C.; Iemmo, L.; Piano, S.; Bobba, F.; Longobardi, M.; Scarfato, A.; Sannino, D.; et al. Multiwalled carbon nanotube films as small-sized temperature sensors. J. Appl. Phys. 2009, 105, 064518. [CrossRef]

14. Lin, L.; Liu, S.; Zhang, Q.; Li, X.; Ji, M.; Deng, H.; Fu, Q. Towards tunable sensitivity of electrical property to strain for conductive polymer composites based on thermoplastic elastomer. ACS Appl. Mater. Interfaces 2013, 5, 5815-5824. [CrossRef] [PubMed]

15. Chu, K.; Lee, S.C.; Lee, S.; Kim, D.; Moon, C.; Park, S.H. Smart conducting polymer composites having zero temperature coefficient of resistance. Nanoscale 2015, 7, 471-478. [CrossRef] [PubMed]

16. Song, K.; Zhang, Y.; Meng, J.; Green, E.C.; Tajaddod, N.; Li, H.; Minus, M.L. Structural polymer-based carbon nanotube composite fibers: Understanding the processing-structure-performance relationship. Materials 2013, 6, 2543-2577. [CrossRef]

17. Rotkin, S.V.; Perebeinos, V.; Petrov, A.G.; Avouris, P. An essential mechanism of heat dissipation in carbon nanotube electronics. Nano Lett. 2009, 9, 1850-1855. [CrossRef]

18. Baloch, K.H.; Voskanian, N.; Bronsgeest, M.; Cumings, J. Remote Joule heating by a carbon nanotube. Nat. Nanotechnol. 2012, 7, 316-319.

19. Celle, C.; Mayousse, C.; Moreau, E.; Basti, H.; Carella, A.; Simonato, J.P. Highly flexible transparent film heaters based on random networks of silver nanowires. Nano Res. 2012, 5, 427-433. [CrossRef]

20. Sui, D.; Huang, Y.; Huang, L.; Liang, J.; Ma, Y.; Chen, Y. Flexible and transparent electrothermal film heaters based on graphene materials. Small 2011, 7, 3186-3192. [CrossRef]

21. Chu, K.; Yun, D.J.; Kim, D.; Park, H.; Park, S.H. Study of electric heating effects on carbon nanotube polymer composites. Org. Electron. 2014, 15, 2734-2741. [CrossRef]

22. Chu, K.; Park, S.H. Electrical heating behavior of flexible carbon nanotube composites with different aspect ratios. J. Ind. Eng. Chem. 2016, 35, 195-198. [CrossRef]

23. Ding, W.; Eitan, A.; Fisher, F.; Chen, X.; Dikin, D.A.; Andrews, R.; Brinson, L.C.; Schadler, L.S.; Ruoff, R.S. Direct observation of polymer sheathing in carbon nanotube-polycarbonate composites. Nano Lett. 2003, 3, 1593-1597. [CrossRef]

24. Karimzadeh, A.; Koloor, S.S.R.; Ayatollahi, M.R.; Bushroa, A.R.; Yahya, M.Y. Assessment of Nano-Indentation Method in Mechanical Characterization of Heterogeneous Nanocomposite Materials Using Experimental and Computational Approaches. Sci. Rep. 2019, 9, 15763. [CrossRef]

25. Kasani, H.; Khodabakhsh, R.; Ahmadi, M.T.; Ochbelagh, D.R.; Razali, I. Electrical properties of MWCNT/HDPE composite-based MSM structure under neutron irradiation. J. Electron. Mater. 2017, 46, 2548-2555. [CrossRef]

26. Celia, E.; de Givenchy, E.T.; Amigoni, S.; Guittard, F. Three steps to organic-inorganic hybrid films showing superhydrophilic properties. Soft Matter 2011, 7, 10057-10062. [CrossRef]

27. Cunha, C.; Panseri, S.; Iannazzo, D.; Piperno, A.; Pistone, A.; Fazio, M.; Marcacci, M.; Galvagno, S. Hybrid composites made of multiwalled carbon nanotubes functionalized with $\mathrm{Fe}_{3} \mathrm{O}_{4}$ nanoparticles for tissue engineering applications. Nanotechnology 2012, 23, 465102. [CrossRef]

28. Stobinski, L.; Lesiak, B.; Kövér, L.; Tóth, J.; Biniak, S.; Trykowski, G.; Judek, J. Multiwall carbon nanotubes purification and oxidation by nitric acid studied by the FTIR and electron spectroscopy methods. J. Alloys Compd. 2010, 501, 77-84. [CrossRef]

29. Goyanes, S.; Rubiolo, G.; Salazar, A.; Jimeno, A.; Corcuera, M.A.; Mondragon, I. Carboxylation treatment of multiwalled carbon nanotubes monitored by infrared and ultraviolet spectroscopies and scanning probe microscopy. Diam. Relat. Mater. 2007, 16, 412-417. [CrossRef]

(C) 2020 by the authors. Licensee MDPI, Basel, Switzerland. This article is an open access article distributed under the terms and conditions of the Creative Commons Attribution (CC BY) license (http://creativecommons.org/licenses/by/4.0/). 